Article

\title{
Drones, Augmented Reality and Virtual Reality Journalism: Mapping Their Role in Immersive News Content
}

\author{
John V. Pavlik \\ Journalism and Media Studies, Rutgers University, New Brunswick, NJ 10516, USA; E-Mail: jpavlik@comminfo.rutgers.edu
} Submitted: 15 March 2020 | Accepted: 28 April 2020 | Published: 27 July 2020

\begin{abstract}
Drones are shaping journalism in a variety of ways including in the production of immersive news content. This article identifies, describes and analyzes, or maps out, four areas in which drones are impacting immersive news content. These include: 1) enabling the possibility of providing aerial perspective for first-person perspective flight-based immersive journalism experiences; 2) providing geo-tagged audio and video for flight-based immersive news content; 3) providing the capacity for both volumetric and 360 video capture; and 4) generating novel content types or content based on data acquired from a broad range of sensors beyond the standard visible light captured via video cameras; these may be a central generator of unique experiential media content beyond visual flight-based news content.
\end{abstract}

\section{Keywords}

augmented reality; drones; journalism; photogrammetry; virtual reality; volumetric

\section{Issue}

This article is part of the issue "Journalism from Above: Drones, the Media, and the Transformation of Journalistic Practice" edited by Jonas Harvard (Mid Sweden University, Sweden), Mats Hyvönen (Uppsala University, Sweden) and Ingela Wadbring (Mid Sweden University, Sweden).

(C) 2020 by the author; licensee Cogitatio (Lisbon, Portugal). This article is licensed under a Creative Commons Attribution 4.0 International License (CC BY).

\section{Introduction}

Drones are playing an increasingly central role in the development of immersive news content production, including in the development of augmented reality, virtual reality and mixed reality (which is essentially a fusion of augmented reality and virtual reality) applications in news content. This essay examines four sets of important implications for immersive news content and its production.

As drones have evolved from analog to digital platforms, their use in journalism has grown slowly but significantly (Chamberlain, 2017; Chapa, 2013; Goldberg, Corcoran, \& Picard, 2013). In their earliest applications, drones were used much as helicopters had been used in newsgathering to obtain aerial perspectives (Pool, 2012). Aerial perspectives are valuable to news users because it can give a new vantage point that allows them to see the bigger picture, patterns not visible from the ground, and even facilitate a sense of wonder, a capacity further enhanced by immersive experiences such as virtual reality or augmented reality.
Notably, drones offered news organizations and individual journalists a much cheaper and safer alternative means to capture aerial perspectives. Guided and shaped by ethical concerns regarding privacy and safety as well as regulatory provisions, drone usage has grown gradually in journalism around the globe (Tremayne \& Clark, 2014). Falling prices and increasing affordability have fueled this growth, as well, although costs for production of augmented reality, virtual reality and mixed reality have been relatively high. We should acknowledge the parallel use of the drone technology in various other contexts such as in sports, in military, crowd control by police (e.g., during the COVID-19 crisis, law enforcement has begun using surveillance drone technology to enforce social distancing regulations) and this can increasingly infringe upon personal freedom, even if it is done for journalistic purposes.

Because of their increasingly miniature and highperformance capacity, including improved battery performance and portability, drones have enabled creative and expanded aerial video and photography capabilities 
including capturing news content indoors, as well as in various novel situations such as for documentary production for extreme sports, pointing toward augmented reality, virtual reality and other immersive applications as well. Underwater drones have also been developed and utilized in newsgathering. Likewise, terrestrial 'drones,' or remotely operated or autonomous land-based robots equipped with cameras and other sensors have been developed for a variety of applications such as to descend into narrow caves or other environments unsafe or otherwise inaccessible for humans including reporters (Coxworth, 2019).

The advent of experiential news (Pavlik, 2019a) has introduced a new set of opportunities for the utilization of drones in journalism. Advances in drone technology as well as in the development of and integration of advanced cameras and various sensors, from night vision to depth or 3D measurement, have enabled at least four arenas for the use of drones in the production of experiential news (Pavlik, 2019b; Peters, 2015). Experiential news utilizes experiential media forms that feature six qualities: interaction, immersion (both audio and video envelopment as well as psychological immersion), multi-sensory content, algorithms and data driven content, first-person perspective, and natural user interface design (e.g., voice or gesture control). Experiential media include augmented reality, virtual reality, mixed reality, which blends these two, and other forms of media that collectively are sometimes referred to as extended reality, as advanced ultra-high definition video systems (e.g., 8K, 240 frames per second, high dynamic range). The journalism industry often refers collectively to these formats as immersive news, but although this is an important quality of the content, it is really only one of a half dozen.

\section{Four Implications of Drones for Augmented Reality, Mixed Reality and Virtual Reality Journalism}

Drones present at least four sets of opportunities or implications for the development of news content utilizing experiential media, including augmented reality, virtual reality and mixed reality in journalism.

\subsection{First-Person Perspective}

First is by using 360-degree cameras, drones can provide the capacity for aerial content (or data) for firstperson perspective flight-based immersive journalism experiences. Aerial perspectives are of particular relevance in this arena because they can enable the news consumer to obtain unique vantage points on news events. Examples from recent news reporting utilizing drones to capture 360-degree or omnidirectional video can help illustrate the importance of the technology. Multiple news operations have used drones equipped with 360-degree cameras to obtain omnidirectional, aerial vantage points for reports about the evolving character of urban en- vironments (6abc, 2019) to refugee movements (Estrin, 2016). Drones that utilize 3D panoramic video or photographic capture can also further support the possibility of more immersive news content.

Climate change and other environmental stories can also benefit from the use of drones in the production of immersive content (Dorroh, 2015). Haner ("Taking visual journalism into the sky," 2018) states:

The first drone images I made were on a trip to Greenland's ice sheet, where I captured images of a meltwater river flowing across the top of the ice. In Llapallapani, Bolivia, I used a drone to show that the second-largest lake in Bolivia had dried up, leaving boats stranded in the sand and a fishing community having to reinvent itself. More recently, I was able to get an aerial angle of the giant moai statues on Easter Island showing their proximity to an eroding coastline, which would not have been possible any other way.

Illustrating the potential for immersive aerial drone video journalism is a 2015 report produced by The New York Times, which used a 360-degree video captured from inside three different refugee camps (Lba, 2015). Viewed via a Google cardboard head-mounted display, the report enabled the user to gain a compelling sense of the life of a displaced person. In one case, the virtual reality camera rig was positioned on the handlebars of a child's bicycle and the omnidirectional video was captured as the child rode about the camp. The user could virtually ride along and look in any direction, hearing the child's voice and other sounds of the refugee camp. By extension, a drone could capture similar omnidirectional and potentially $3 \mathrm{D}$ imagery if equipped with the required imaging technology in a wide spectrum of stories, from empty city streets during the COVID-19 crisis to surveying the devastation of brush fires in California (Owen, Pitt, Aronson-Rath, \& Milward, 2015).

Drones operating in other environments such as underwater or on land extend this capacity further. The BBC employed a robotic drone designed to look like a tuna to capture under water video of a dolphin megapod swimming near Costa Rica (Lopez, 2014). The combination of robotics and underwater drones in fact has potentially wide spread application in journalism, especially immersive forms, so to speak. Illustrative are the growing number of long-lost shipwrecks around the world have been discovered in recent years and months via robotically controlled underwater drones. In one case, a drone using sonar discovered the WWII aircraft carrier USS Hornet lost during the battle of Santa Cruz in October 1943. The drone located the ship more than five kilometers below the surface of the South Pacific Ocean, not far from the Solomon Islands (Fingas, 2019). Video and photos of the wreck have been used in news reporting about the discovery, and future drone expeditions that utilize 360-degree video or 3D image capture could facilitate more immersive news reporting (Fingas, 2019). 
It is especially worth noting the highly skilled autonomous flight capacity of robotic drones (D'Andrea, 2013). Such drones can operate in a wide range of indoor or outdoor environments without direct human operation, although continuous observation is essential for security reasons, as well as safety. Yet, such robotic drones can fly into potentially dangerous situations where a human journalist or pilot could not. Such was the case in a report about an erupting volcano in Iceland. Two drones flew in; one was destroyed. The other suffered serious damage from the extreme heat, including the melting of the camera, but not until after it had obtained rare and remarkable video and the memory stick survived (Rose, 2014).

It is important to note that not all drone video or image capture will necessarily support the creation of immersive or experiential news content. Drone flights equipped with standard field-of-view 2D cameras can capture important scale, context and perspective to a landscape. Yet, such cameras do not enable the generation of imagery or video that can surround or immerse the viewer (unless there are multiple cameras obtaining multiple video streams that are subsequently stitched together, such as via the Google Jump virtual reality rig, which has been used by news organizations such as The New York Times). Moreover, standard video cameras do not allow for interactivity between the viewer and the environment beyond family video control functions (e.g., pause, rewind, fast forward). Drones equipped with 3D, 360-degree camera systems could enable more user interactivity.

\subsection{Geo-Tagged Audio and Video}

The second implication of drones for immersive news is to provide geo-tagged audio and video for flight-based (or terrestrial or underwater) immersive news content (Pavlik, 2014). This capacity enables the generation of immersive content experienced in a geo-located context. To date, there are few industry examples to draw upon as illustration of the potential of geo-located dronegenerated reporting. But one limited example suggests the possibilities. Some drones, including those of the leading provider from China, DJI, has introduced a platform for full motion video geotagging capabilities, including longitude, latitude and altitude (Remotegeo, 2019). This technology enables journalists (or anyone else) to create map-based immersive video playback that can precisely overlay visually the location of the aerial video onto terrestrial locations, enabling the viewer to see and understand the mapping location. This can be especially important in providing before-and-after video imagery, such as in a story about climate change, a report about a natural disaster (e.g., a wildfire, earthquake, tsunami, etc.), a refugee camp or migration patterns, civil unrest or protests, or other scenes where visualizing change over time is a critical part of the narrative (Corcoran, 2015; Hauser, 2013; Visser, 2016; Wilson, 2014).
News media have already started producing geotagged content, though distributing such material captured via drone has yet to emerge. In early 2020, National Geographic produced an interactive, immersive augmented reality news experience for Earth Day 28 April, and distributed via Instagram (National Geographic, 2020). Users interact with a 3D visualization depicting what Earth will be like in 2070 given patterns in climate change and carbon emissions. Such an immersive narrative developed using 3D geo-tagged drone video or photographs could give users an additional layer of understanding of a critically important story.

\subsection{Volumetric 360-Degree Video and 3D Audio}

The third implication of drones for immersive news is the capacity for both volumetric and 360-degree video and 3D audio capture (as well as other 3D data). Volumetric capture incorporates 3D data and when combined with high-resolution imagery enables 'photogrammetry' capabilities (i.e., maximum accuracy) for ultravirtual presence in news experiences (Keyser, Chryssos, \& Buchleitner, 2019a). Photogrammetry is a map-making technology that uses photography and was invented in 1851 by French inventor Aimé Laussedat, although it has been advanced significantly in the digital age and in applications via drones especially for terrestrial surveying (Britannica, 2019). Although photogrammetry in general can be generated using a smartphone (Keyser et al., 2019b), producing it via drones in particular requires special technology. One approach is to develop a "custom-built hexacopter to capture smooth 360-degree aerial video content for news organizations and film productions using a custom gimbal (for stabilization) commissioned for this solution" (King, 2018). Capturing binaural 3D audio is also a potentially valuable capability via drone (Tépper, 2019). Binaural refers to audio for both ears, and to capture such audio in 3D forms requires multiple microphones positioned to capture depth information and precise sound source location. Although this approach has not yet been employed in drone journalism, it could prove important to immersive drone news for an authentic user experience.

Another approach to generating photogrammetry involves Light Detection and Ranging (LiDAR), or laser scanners (using time of flight, triangulation or interferometry), to scan an area and return $x, y$, and $z$ 3D coordinates for multiple points on an object or in an area. Photographs and video enabled by photogrammetry can define the edges of buildings and thereby allow journalists to generate precise 3D models or renderings of news environments (Grut, 2019). Capturing and producing photogrammetry via drones requires Light Detection and Ranging or other sensor technology that is relatively small in size, and is increasingly available at low cost, even for use in smartphones.

Paris-based Parrot has also developed drone video acquisition systems that generate photogrammetry- 
designed content. In particular, the company employs Pix4D visualization tools to acquire video with precise time-stamped 3D coordinates (Parrot, 2016). Others have as well (Paladrone, 2016). Pix4D is a Swiss company whose system uses a combination of computer vision algorithms and photogrammetry to transform digital single-lens reflex, Red-Green-Blue, thermal and multispectral images into 3D models and 3D maps (Pix4D, 2019).

Drone-produced photogrammetry enables the production of experiential media news content with six degrees of freedom, vital for fully immersive augmented reality/virtual reality/mixed reality news content (e.g., beyond simple 360-degree video). These six degrees of freedom include rotational (i.e., enabling the user to look in any direction, as in 360-degree video) and translational (i.e., enabling the user to move in any direction, which is especially relevant for virtual flight). Combined, these six degrees of freedom can generate a user news experience with a heightened sense of presence and authenticity in the news venue. Cadoux (2019) argues that creating spatial content will be transformative to journalism:

The most significant divergence from traditional media is the introduction of user-directed spatial dynamics, adding a new level of presence to readers. This will bring the concept of 'spatial journalism' to the forefront of the industry.... Instead, it may use 3D imagery to immerse you, putting you in the cinematographer's shoes. Imagine walking through a war zone, flying over 3D terrain maps, analyzing interactive data sets, standing next to Mick Jagger on stage, or bumping in a rover on Mars.

Drones using photogrammetry technology will be instrumental in the production of such news content.

A particular benefit of drone production for augmented reality/virtual reality/mixed reality news content is the utilization of improved efficiencies in automated, algorithm enabled data capture and postproduction. Such drone-based augmented reality/virtual reality/mixed reality production has widespread application to news content topics from climate change to natural disasters to conflict zones and refugee situations.

Another important benefit of volumetric drone video 3D capture especially via photogrammetry is improved accuracy. Accuracy in reporting long has been a key dimension of quality journalism. Accuracy establishes the basis for public trust in the facts as reported. By capturing high-resolution 360-degree photographs and video encoded with precise 3D data, immersive drone reporting can generate news content that offers the public facts that can be trusted and relied upon to understand the truth in journalism and the content it provides.

A revealing illustration of the potential of improved accuracy through 3D data captured from above ground, including via satellite, is improved reporting on stories about the melting of glaciers in the Himalayas (Qiu,
2012). Measuring precisely how quickly the glaciers are melting has proven difficult, but a series of studies of the melting Himalayan glaciers has measured their surface elevations with a laser altimeter to improve accuracy. "It was designed for smooth topography of the polar regions and cannot be readily used to map rough terrains such as the Himalayas," says Andreas Kääb (Qiu, 2012), a remotesensing authority at the University of Oslo in Norway. The researchers corrected the data using elevation measurements from the Shuttle Radar Topography Mission. Similar data collected via drone today could enable improved accuracy in both scientific inquiry as well as in news reporting about the rate of glacial melt, a key consequence of climate change and a matter often contested for political reasons. Providing more accurate, reliable data via drone for immersive news content would offer the public journalism it could better trust. The value of data-driven virtual reality content can enhance its credibility in the same manner that data-based facts in other realms of news content can increase its reliability.

Among the potential benefits is the potential for creating haptic journalism (Pavlik \& Feiner, 2018). Pavlik and Feiner (2018, p. 1) state: "Haptic interfaces present an opportunity to create a new form of storytelling in journalism. These interfaces communicate through hapticsthe bodily sensations of touch, pressure, vibration, temperature, pain, and proprioception." Pavlik and Feiner $(2018$, p. 2) outline the potential relevance of haptics to news content:

Applying haptic interaction to create haptic journalism could aid news consumers in understanding a variety of stories, from science to the environment, allowing them to feel the data. We propose to explore haptic journalism by creating haptic interfaces for data visualizations, or data maps, based on U.S. Census data. An important benefit of haptic journalism is that it can provide a means to enable visually impaired users to experience and interact with these (haptic) visualizations.

Volumetric drone news content enables the potential to offer news users the capability to explore and experience aerial immersive news through a haptic interface, such as a data glove. Such an interface could be useful for the visually impaired, but also for news consumers in general as an additional sensory dimension of news engagement. It might allow users to virtually feel the density of particulate matter in the atmosphere as it varies by time or place.

Research shows that engagement in virtual environments, particularly those that utilize haptic or other multisensory interfaces, can increase the user's sense of presence in the story, empathy with individuals in the news, and concern about or understanding of a wide range of issues from deforestation to melting glaciers (Rogers, 2019). Utilizing haptic content interfaces generated from 3D drone volumetric capture could prove effective in increasing public empathy for and understand- 
ing of vital issues such as climate change. Such outcomes are key in enabling the user to become more than simply a news consumer; and instead become a virtual participant in the news or a virtual witness to news events.

Illustrating the potential of this drone-generated volumetric content is Time's immersive Amazon rainforest experiential report from 2019 ("Inside the Amazon," 2019). The augmented reality experience was generated using a variety of newsgathering technologies. Among them were "drone photography and 3-D photogrammetry of some of the most remote, difficult-to-reach and threatened locations that takes readers deep into the disappearing Amazon in a way never seen before ("Inside the Amazon," 2019). The immersive journey:

Follows a team of journalists Time sent deep into the Amazon. There, they met the indigenous people fighting illegal logging, the loggers cutting paths into the jungle, and the frontiersmen and women making an illicit living from the land. Guided by renowned primatologist and environmentalist Jane Goodall, you'll explore tribal villages, inspect lumberyards and see for yourself how the Amazon is under threat. ("Inside the Amazon," 2019)

By using drones to capture 3D high-resolution imagery, the report enables users to observe and explore the character and destruction of the Amazon from a perspective that can provide greater contextualization. Research shows that virtual reality content that enables the user to experience phenomena from alternative perspectives can build long-term empathy (Herrera, Bailenson, Weisz, Ogle, \& Zaki, 2018).

Immersive, drone-produced stories might feature news experiences in which the user can engage in virtual flight, as has been done in some documentary productions and other non-fiction immersive experiences (Hynes, 2015). One notable example is an immersive virtual flight production created for visitors to the Space Needle in Seattle (Tracy, 2015). Using drones equipped with 360-degree, depth-sensing cameras, the Space Needle Visitor Center has designed an immersive experience for visitors who don a virtual reality headset (Space Needle Visitor Center, 2019). Once wearing the headset, visitors can fly virtually around the exterior of the Space Needle at 605 feet above the street to obtain the view of the tourist attraction from the vantage point of the so-called Halo Walk, normally off limits to visitors.

It should be noted that for users to fully experience immersive drone video journalism requires the user to don a head-worn display (e.g., a virtual reality headset such as the Oculus Quest; Community Content, 2020). Likewise, to fully experience augmented-reality generated drone news content requires the user to access that augmented reality via a digital device such as a smart phone or an augmented reality-headset.

A recent report from Quartz illustrates even more advanced immersive, drone-generated capabilities. Titled
The 2050 Project, Quartz (Johnson, 2019; "The 2050 project," 2019) utilized advanced drone technology to capture a wide spectrum of 3D data about cities. As the report states, "by 2050, two-thirds of the world's population will live in cities. We explore creative solutions to the challenges of urban living" (Johnson, 2019). They do this by using advanced drone and other technologies for volumetric news gathering, including photogrammetry, in order to produce an augmented reality news package (Johnson, 2019).

Johnson provides important context to explain how and why Time employed these tools in its immersive report:

To see the evolution of how we can use 3D imagery and aspects of virtual reality in city planning, retail, education, and journalism, look no further than augmented reality (augmented reality). This technology has been used in test cases in journalism, but never has augmented reality been the backbone of a series of stories and so deeply integrated into the editorial process. (Johnson, 2019, p. 1)

Simply put, the goal of the report was to "use augmented reality to better understand what cities will look like in 2050" (Johnson, 2019, p. 1). The authors explain they chose to use augmented reality because of its advantage in better illustrating context. Moreover, this was amplified by using aerial drone video. Combined, the tools enabled Quartz to "put our views into perspective and build healthy discussions on complex issues" (Johnson, 2019).

Quartz combined the 3D data, video and photographs to generate models of buildings and other objects in the cities reported on. Through augmented reality the report enabled users (i.e., news consumers accessing the content via their mobile app) to experience on their phone (or other digital device) objects that:

Aren't just architectural renderings-they are photorealistic models. They show how a building fits in living with the environment around it, how people are using it. They offer a snapshot in time that reflects the role of a particular place in its community, and how that place evolves. (Johnson, 2019)

This is essential context. Quartz adds that "The models inform the future, too-you can begin to build your own understanding of why community-driven solutions help lift cities into becoming healthier and more prosperous for the people who live there" (Johnson, 2019).

Quartz explains that they created the augmented reality models using photogrammetry. This required a multi-stage process:

First, we captured hundred of images of the building, shot from the ground and by drones. Then, AutoDesk Recap Photo, (the photogrammetry software we used), looked at every pixel in each photo 
and compared them across all of the photographs to measure distance. It then built hundreds of thousands of triangles that are made up of these measurements and built a 3D model. It then took the pictures to overlay a skin or texture onto the 3D model, which gives you the final product. (Johnson, 2019)

Others have similarly examined the role of 3D generated drone video and photography in immersive news content (Ntalakas, Dimoulas, Kalliris, \& Veglis, 2017, p. 194). They explain: "Refinement is possible through motion analysis and image-matching (i.e., near-duplicate detection and other similar techniques), while GPS and time-related information can be further utilized along with user-provided metadata." The consequences of such drone-generated 3D news content may be far reaching, including in leading to alternative audience perceptions of news subject matter. Ntalakas et al. (2017, p. 194), explain:

In general, different users will focus on the part of the story they find interesting (in any context), so practically they capture different parts and/or views of the same event (Dimoulas \& Symeonidis, 2015). This plurality of streams offers the wanted multiple viewpoints, which can be combined and enhanced, augmenting audience interaction and engagement through immersive storytelling experiences (i.e., multi-view selection, augmented reality projection, location and language adaptation, channel-and terminal-oriented playback, 3D reproduction, panoramic and time-lapse virtual navigation, etc.). Specifically, in the newsgathering case, reporters (professional journalists and/or UGC-users) impose their own subjective point of view, either unintentionally or purposely (this is usually reflected on the involved audiovisual captures, but also on the textual comments and reportages).

\subsection{Generate Novel Content Types}

The fourth implication of drones for immersive news is to generate novel content types or content based on data acquired from a broad range of sensors including 3D photogrammetry as well as electromagnetic spectrum data beyond the standard visible light captured via video cameras. These may be a central generator of unique experiential media content beyond visual flight-based news content. This approach is one that highlights innovation in the news production process, and therefore requires a certain amount of risk-taking and boldness of vision, as there is always the risk of failure with any new initiative. As a new tool for reporting, drones offer new capacities for storytelling in the immersive realm. As Harvard and Lindblom (2019, p. 11) have stated, "Journalism continually adds new tools for storytelling." The key is doing so effectively and maintaining the news values that make journalism essential to society: "The negotiation regarding how to integrate such tools in relation to existing norms, values and practices often reveal underlying, sometimes unspoken, professional identities" (Harvard \& Lindblom, 2019, p. 11).

Experiential media are immersive but feature several additional capacities for journalism content including interactivity, multi-sensory engagement, and natural user interface design (e.g., user control by gaze approximation or voice). Drone captured content is central. Combined, the features of experiential media ultimately give the news user the capacity to virtually experience news events and issues as if present as a participant or eyewitness in flight or other drone-generated contexts. Natural user interface enables the user to have an intuitive level of control over their navigation through the content experience or news story. Research indicates such immersion can enhance user engagement, sense of presence, empathy and understanding of the news. Foer (2011) has outlined how spatial understanding fundamentally shapes human memory. Spatial content is a basic characteristic of volumetric news content.

Among these capabilities is the enabling of multiple users to simultaneously experience immersive drone video or other types of data (e.g., visualizations generated from atmospheric data such as particulate matter measuring air pollution or smoke from fires) either in real-time or from a recorded news experience. Key to this is the development of $5 \mathrm{G}$ wireless services, which will enable broadband (high-speed Internet) across urban areas and beyond as well as immersive drone reporting in realtime or near real-time (i.e., low latency) situations such as during breaking news (Horwitz, 2019).

One drone system developed for this purpose has been tested at the Technological University of Crete, Greece (Libelium, 2019):

Drones equipped with compact sensors can provide data at nearly any point in a 3D axis. This interesting characteristic favors the reduction of sensor nodes used in every smart cities or smart environment project, diminishing the total cost of the solution. Additionally, permits the user to obtain local data for production monitoring, problem detection and local climate control.

Among the measures that can be captured in 3D format are air temperature, atmospheric pressure, humidity, carbon monoxide, carbon dioxide, sulfur dioxide, ozone, nitrogen dioxide, and ammonia. Journalism could employ such data captured via drone to provide immersive news offerings an entirely new perspective on cities and other locations around the world (i.e., enabling users to see or otherwise experience phenomena not visible to the human eye). Tracking over time could enable greatly expanded understanding the context to that 3D dronebased reporting.

A somewhat theoretical example here might effectively illustrate the potential use of drones in this regard. In particular, equipping drones with sensors that could 
capture haptic data (e.g., tactile data, perhaps from surfaces observed) would enable the creation of news narratives that offer the user a more tangible news experience. The Oculus Quest has emerged as a popular, untethered virtual reality platform with haptic, handheld controllers. Designing news experiences that not only enable the user to enter an enveloping news experience visually and aurally, but also with haptic engagement could heighten the realism of those stories.

Fueling all four of these applications of drone technology for immersive journalism is the rise of cloud computing and its utilization in providing sufficient bandwidth and distributed Al data processing to enable live and broadband capabilities, a key factor in volumetric, photogrammetry in drone journalism (Dimoulas \& Symeonidis, 2015; Dimoulas, Veglis, \& Kalliris, 2014).

It is worth noting that many of the technologies needed to generate the immersive drone content described in this article are as of this writing expensive and complex to use. Small newspapers and television stations may find these capabilities out of reach as of now, unless they collaborate with larger news organizations or technology partners. For the most part, it is only major national and international companies such as The New York Times, Time and National Geographic who can afford the requisite drone technology, personnel and production tools. Yet, if past is prologue, it is likely the cost and technical complexity of the needed tools are likely to decline in coming months and years, and the quality is likely to improve, and these developments will make drone-produced immersive journalism more accessible to local TV stations and other local news media (Carey \& Elton, 2010).

\section{Concluding Reflections}

This essay has outlined four sets of implications regarding the use of drones in creating augmented reality, virtual reality and mixed reality journalism. These are: 1 ) providing aerial perspective for first-person perspective flightbased immersive journalism experiences; 2) providing geo-tagged audio and video for flight-based immersive news content; 3 ) providing the capacity for both volumetric and 360-degree video capture; and 4) generating novel content types or content based on data acquired from a broad range of sensors beyond the standard visible light captured via video cameras; these may be a central generator of unique experiential media content beyond visual flight-based news content.

It is critical to note that although these implications bring a variety of potential benefits to news content, including more engaging and more accurate reporting, there are possible adverse consequences as well. Among these adverse implications are the possible accidental or intentional misuse of drones to create immersive news content that is compelling, apparently real, but a new class of deep fakes from an aerial perspective (Pavlik, 2019b).
Moreover, it is imperative that journalists and news media employing drones in the production of immersive news adhere to the highest ethical standards in order to maximize public trust (Culver, 2014; Jarvis, 2014; Tompkins, 2017). Developing clear industry guidelines for the ethical use of drones in producing immersive journalism is a key next step (Waite \& Kreimer, 2017). Keyser et al. (2019a), identify four ethics-related questions journalists using photogrammetry and 3D modeling should ask, including for drone production. These are: 1) whether the entire story will be told using photogrammetry; 2) whether the story is about exploration or discovery; 3 ) will the "model have visual/visceral impact while it is motionless" (p. 1); and 4) will the reporter (or drone operator) have "control to get your location and subject to remain motionless long enough to capture every image you need to reconstruct the model?" (p. 1). Per question four, this may not be a problem for objects such as buildings, but for subjects more animated (e.g., people, animals, etc.), it may be a significant challenge.

Future research should explore several important research questions regarding the use of drones in generating immersive news content. First, research should examine the impact of drone-generated immersive news content experienced either from aerial or underwater perspective on user empathy and other effects. Although existing research suggests such immersive experiences can shape user affect and understanding, it is essential to assess such content experiences within a dronegenerated context. Second, drone-generated immersive news should be studied for any unintended consequences that flight (or underwater) based experiences could produce. Finally, research should examine the potential impact that the use of drones in producing immersive news has on journalistic practice, including workload and possible ethical considerations. Especially because nonverbal data tracking is a significant part of the virtual reality experience, designing such immersive news content designed to protect user privacy is essential (Bailenson, 2018).

\section{Acknowledgments}

The author thanks Professor Harvard Jonas, Mid Sweden University, for inviting him to participate in the Journalism from Above Workshop, Sunsdvall, Sweden held 18-20 September 2019; it was the inspiration for this article.

\section{Conflict of Interests}

The author declares no conflict of interests.

\section{References}

6abc. (2019, October 14). Drone 360 brings more immersive viewing to action news. 6abc.com. Retrieved from https://6abc.com/technology/drone- 
360-brings-more-immersive-viewing-to-actionnews/5618201

Bailenson, J. N. (2018). Protecting nonverbal data tracked in virtual reality. JAMA Pediatr, 172(10), 905-906.

Britannica. (2019). What is photogrammetry. Britannica. Retrieved from https://www.britannica.com/ science/photogrammetry

Cadoux, M. (2019, November 10). Augmented reality and virtual reality will make spatial journalism the future of reporting. Venture Beat. Retrieved from https://venturebeat.com/2019/11/10/ar-and-vrwill-make-spatial-journalism-the-future-of-reporting

Carey, J., \& Elton, M. (2010). When media are new: Understanding the dynamics of new media adoption and use. Ann Arbor, MI: The University of Michigan Press.

Chamberlain, P. (2017). Drones and journalism. New York, NY: Routledge Press.

Chapa, L. (2013). Drone journalism begins slow take off. News Media and the Law, 37(2), 9-10.

Community Content. (2020, January 20). Haptic feedback with Oculus Quest could be the next step in immersion. Virtual Reality League. Retrieved from https://vrleague.gg/2020/01/30/haptic-feedbackwith-oculus-quest-is-here

Corcoran, M. (2015, January). Drone journalism: Newsgathering applications of unmanned aerial vehicles (UAVs) in covering conflict, civil unrest and disaster (Introductory Paper). Ultimo: Australian Broadcasting Corporation. Retrieved from https:// assets.documentcloud.org/documents/1034066/ final-drone-journalism-during-conflict-civil.pdf

Coxworth, B. (2019, November 4). Steve is a groundgoing equivalent to aerial camera drones. Newatlas. Retrieved from https://newatlas.com/drones/stevewheeled-camera-drone

Culver, K. B. (2014). From battlefield to newsroom: Ethical implications of drone technology in journalism. Journal of Mass Media Ethics, 29, 52-64.

D'Andrea, R. (2013). The astounding athletic power of quadcopter. TED. Retrieved from https://www.ted. com/talks/raffaello_d_andrea_the_astounding_ athletic_power_of_quadcopters?language=en

Dimoulas, C., \& Symeonidis, A. (2015). Syncing shared multimedia through audiovisual bimodal segmentation. IEEE Multimedia Magazine, 22(3), 26-42.

Dimoulas, C., Veglis, A., \& Kalliris, G. (2014). Application of mobile cloud-based technologies in news reporting: Current trends and future perspectives. In J. Rodrigues, K. Lin, \& J. Lloret (Eds.), Mobile networks and cloud computing convergence for progressive services and applications (pp. 320-343). Hershey, PA: IGI Global.

Dorroh, J. (2015). Environmental reporting and media development: equipping journalists with the training and tools to cover a critical beat. Center for International Media Assistance. Retrieved from http://www.cima.ned.org/publication/ environmental-reporting-media-development

Estrin, J. (2016, December 28). Photographing climate change refugees, by drone and on foot. The New York Times. Retrieved from https://lens.blogs. nytimes.com/2016/12/28/photographing-climatechange-refugees-drone-foot-josh-haner

Fingas, J. (2019, February 12). Sonar drone discovers long-lost WWII aircraft carrier USS Hornet. Engadget. Retrieved from https://engadget.com/amp/2019/ 02/12/paul-allen-expedition-discovers-uss-hornet

Foer, J. (2011). Moonwalking with Einstein: The art and science of remembering everything. New York, NY: Penguin Books.

Goldberg, D., Corcoran, M., \& Picard, R. (2013). Remotely piloted aircraft systems and journalism. Oxford: Reuters Institute for the Study of Journalism. Retrieved from https://reutersinstitute.politics.ox. ac.uk/sites/default/files/Remotely\%20Piloted\% 20Aircraft\%20and\%20Journalism_0.pdf

Grut, S. (2019). A new dawn for $3 d$ tech in journalism. Niemanlab. Retrieved from https://www. niemanlab.org/2018/12/a-new-dawn-for-3d-techin-journalism

Harvard, J., \& Lindblom, T. (2019). News shouldn't look good: Swedish photo journalists' attitudes towards the aesthetic and journalistic values of drone photography. Paper presented at the Journalism from Above Workshop, Sunsdvall, Sweden.

Hauser, C. (2013, December 12). In Thailand, a drone's eye view of protests. The New York Times. Retrieved 28 April 2020 from http://thelede.blogs. nytimes.com/2013/12/02/in-thailand-a-drones-eyeview-of-protests

Herrera, F., Bailenson, J. N., Weisz, E., Ogle, E., \& Zaki, J. (2018). Building long-term empathy: A largescale comparison of traditional and virtual reality perspective-taking. PLOS ONE, 13(10). https://doi. org/10.1371/journal.pone.0204494

Horwitz, J. (2019, October 18). Verizon debuts GPUbased $5 \mathrm{G}$ edge services for mobile virtual reality/XR developers. Venture Beat. Retrieved from https://venturebeat.com/2019/10/18/verizondebuts-gpu-based-5g-edge-services-for-mobile-vrxr-developers

Hynes, E. (2015, January 24). Finding meaning in virtual reality. Sundance. Retrieved from http:// www.sundance.org/blogs/news/finding-meaning-invirtual-reality--a-closer-look-at-new-frontier

Inside the Amazon: The dying forest AR experience. (2019, September 12). Time. Retrieved from https://time.com/longform/inside-amazon-rainforest-vr-app

Jarvis, J. (2014). The ethical debate of drone journalism: Flying into the future of reporting (Research Paper 475). Carbondale, IL: Southern Illinois University.

Johnson, S. (2019, March 20). A behind the scenes look at how AR can transform the world of journalism. Quartz. Retrieved from https://qz.com/ 
1574453/drones-and-ar-models-are-now-at-theforefront-of-photojournalism

Keyser, H., Chryssos, T., \& Buchleitner, J. (2019a). Photogrammetry for journalism: Documenting reality in 3D. KnightLab. Retrieved from https:// studio.knightlab.com/results/photojournalism3D/ how-to-use-photogrammetry-for-journalism

Keyser, H., Chryssos, T., \& Buchleitner, J. (2019b). 3D modeling in the field: Capturing people for photogrammetry with a smartphone. KnightLab. Retrieved from https://studio.knightlab.com/results/ photojournalism3D/photogrammetry-3d-modelingin-the-field

King, S. (2018, February 2). How to shoot aerial 360 video on a drone. Medium. Retrieved from https://medium.com/reese-innovate/how-toshoot-aerial-360-video-on-a-drone-1484afc0079c

Lba, A. (2015, October 22). New York Times launches virtual reality app, delivers 1 million Google Cardboards to print subscribers. New Yord Daily News. Retrieved from http://www.nydailynews.com/news/national/ ny-times-launches-vr-app-ships-1-million-googlecardboards-article-1.2407586

Libelium. (2019, February 5). 3D air quality modeling with drones in Greece. Libelium. Retrieved from http://www.libelium.com/3d-air-quality-modelingwith-sensor-drones-in-greece

Lopez, J. (2014, January 6). BBC documentary teaches about dolphin megapods in Costa Rica. BBC. Retrieved from http://news.co.cr/bbc-documentaryteaches-about-dolphin-megapods-in-costa-rica/ 31250

National Geographic. [natgeo]. (2020, April 13). What will the world feel like in 2070? [Instagram video]. Retrieved from https://www.instagram.com/p/B7Skn9jbWQ

Ntalakas, A., Dimoulas, C. A., Kalliris, G., \& Veglis, A. (2017). Drone journalism: Generating immersive experiences. Journal of Media Critiques, 3(11), 187-199.

Owen, T., Pitt, F., Aronson-Rath, R., \& Milward, J. (2015, November 11). Virtual reality journalism. New York, NY: The Tow Center for Digital Journalism. Retrieved from https://www.cjr.org/tow_ center_reports/virtual_reality_journalism.php

Paladrone. (2016, November 16). Photogrammetry: Flight planning with Pix4D capture [Video file]. Retrieved from https://www.youtube.com/watch?v=afgno59QcQ

Parrot. (2016). Parrot + Pix4D: 3D reconstruction at Nantes [Video file]. Retrieved from https://www. youtube.com/watch?v=MX_t9MwMyjU

Pavlik, J. V. (2014, October 20). Quadricopters and geolocated video: Implications of drones for the broadcasting, media and film industry. Paper presented at the International Conference on Broadcasting Media \& Film Industry, Baltimore, MD.

Pavlik, J. V. (2019a). Experiential media and transform- ing storytelling: A theoretical analysis. The Journal of Creative Industries and Cultural Studies, 3, 46-67.

Pavlik, J. V. (2019b). Journalism in the age of virtual reality: How experiential media are transforming news. New York, NY: Columbia University Press.

Pavlik, J. V., \& Feiner, S. (2018). Haptic journalism: A proof-of-concept trial. New York, NY: Tow Center for Digital Journalism.

Peters, J. (2015, December 11). And now drones can take pictures at night. Slate. Retrieved from http://www.slate.com/blogs/future_tense/2015/ 12/11/drones_can_take_pictures_at_night_with_ dji_s_zenmuse_xt_camera.html

Pix4D. (2019). Measure from images: A unique photogrammetry software suite for drone mapping. Pix4D. Retrieved from https://www.pix4d.com

Pool, B. (2012, November 12). Obituary: John D. Silva, 92; TV engineer devised the world's first news helicopter. The Washington Post, p. B6.

Qiu, J. (2012, August 22). Himalayan glacier data shift to the middle ground. Nature. Retrieved from https://www.nature.com/news/himalayan-glacierdata-shift-to-the-middle-ground-1.11252

Remotegeo. (2019). Mapping DJI drone video for GIS with video geotagger. Remotegeo. Retrieved from https://www.remotegeo.com/mapping-dji-dronevideo-for-gis-with-video-geotagger

Rogers, S. (2019, November 1). Could virtual reality make us care more about climate change? Forbes. Retrieved from https://www.forbes.com/sites/ solrogers/2019/11/01/could-virtual-reality-makeus-care-more-about-climate-change

Rose, C. (2014, October 2). Watch: Amazing video of volcano erupting in Iceland. CBS News. Retrieved from http://www.cbsnews.com/videos/watch-amazingvideo-of-volcano-erupting-in-iceland

Space Needle Visitor Center. (2019). Experience the wow. Space Needle Visitor Center. Retrieved https://www. spaceneedle.com/experience

Taking visual journalism into the sky with drones: How do New York Times journalists use technology in their jobs and in their personal lives? (2018, May 2). The New York Times. Retrieved from https:// www.nytimes.com/2018/05/02/technology/ personaltech/visual-journalism-drones.html

Tépper, A. (2019, July 10). Record 3D binaural audio with Hooke Verse hardware and software, for Android, iOS + more. Provide Location. Retrieved from https://www.provideocoalition.com/record-3dbinaural-audio-with-hooke-verse-hardware-andsoftware-for-android-ios-more

The 2050 project. (2019, March 27). Quartz. Retrieved https://qz.com/se/the-2050-project

Tompkins, A. (2017). Help drone journalism grow responsibly. National Press Photographers Association. Retrieved from https://nppa.org/magazine/dronecode-ethics

Tracy, B. (2015, December 31). Seattle's Space Needle 
gets an upgrade for the digital age. CBS News. Retrieved from http://www.cbsnews.com/news/ seattle-space-needle-uses-digital-technology-tocreate-new-experience-for-visitors

Tremayne, M., \& Clark, A. (2014). New perspectives from the sky: Unmanned aerial vehicles and journalism' Digital journalism, 2(2), 232-246.

Visser, N. (2016, February 2). Syrian city shown utterly destroyed after 5 years of war. Huffington Post. Retrieved from http://www.huffingtonpost.com/2016/ 02/02/homs-syria-drone-video_n_9146110.html

Waite, M., \& Kreimer, B. (2017). Drone journalism lab operations manual. Digital Commons. Retrieved from http://digitalcommons.unl.edu/cgi/viewcontent. cgi?article $=1097 \&$ context=journalismfacpub

Wilson, B. (2014, March 12). Drone captures e-Harlem explosion scene. New York Daily News. Retrieved from http://www.nydailynews.com/new-york/uptown/ drone-captures-e-harlem-explosion-scene-videoarticle-1.1719988

\section{About the Author}

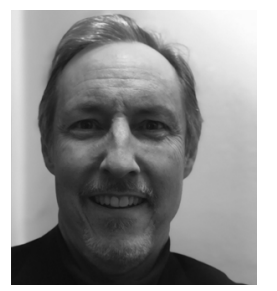

John V. Pavlik is Professor in the Department of Journalism and Media Studies in the School of Communication and Information at Rutgers, the State University of New Jersey. Pavlik's books include Journalism in the Age of Virtual Reality (Columbia University Press), Converging Media, with Shawn Mclntosh (Oxford University Press) and Mobile Disruptions in the Middle East, with Everette E. Dennis, Rachel Davis Mersey and Justin Gengler (Routledge Press). 